\title{
Fulminant Type 1 Diabetes Mellitus Accompanied by Positive Conversion of Anti-insulin Antibody after the Administration of Anti-CTLA-4 Antibody Following the Discontinuation of Anti-PD-1 Antibody
}

\author{
Michiru Shiba ${ }^{1}$, Hidefumi Inaba ${ }^{1}$, Hiroyuki Ariyasu ${ }^{1}$, Shintaro Kawai ${ }^{1}$, Yuko Inagaki ${ }^{1}$, \\ Shohei Matsuno ${ }^{1}$, Hiroshi Iwakura ${ }^{1}$, Yuki Yamamoto ${ }^{2}$, Masahiro Nishi ${ }^{1}$ and Takashi Akamizu ${ }^{1}$
}

\begin{abstract}
:
An 80-year-old woman with malignant melanoma received 20 cycles of anti-programmed death 1 (PD-1) antibody (nivolumab) treatment and showed normal glucose tolerance. Three weeks after switching to anticytotoxic T-lymphocyte associated antigen 4 (CTLA-4) antibody (ipilimumab), her plasma glucose level was elevated to $639 \mathrm{mg} / \mathrm{dL}$, her $\mathrm{HbA1c}$ was $7.7 \%$, and her fastening serum C-peptide immunoreactivity was undetectable. Anti-glutamic acid decarboxylase and insulinoma-associated protein-2 antibodies were negative. She was diagnosed with fulminant type 1 diabetes mellitus (F1DM). Remarkably, her anti-insulin antibody was positively converted, and her Sialylated Carbohydrate Antigen, Krebs von den Lungen-6 levels increased after ipilimumab therapy. She possessed F1DM-susceptible Human Leukocyte Antigen-DR4. A fluorescence activated cell sorting analysis showed an altered T-cell population. This case of F1DM highlights specific mechanisms underlying pancreatic beta cell immunity.
\end{abstract}

Key words: immune-checkpoint inhibitors, PD-1, CTLA-4, fulminant type 1 diabetes mellitus, insulin, pancreatic beta cell

(Intern Med 57: 2029-2034, 2018)

(DOI: 10.2169/internalmedicine.9518-17)

\section{Introduction}

Cytotoxic T-lymphocyte associated antigen 4 (CTLA-4) is a molecule expressed on the surface of activated T-cells, to inhibit the binding of CD28 on the T-cell to B7 on antigenpresenting cells (1). The CTLA-4 pathway preferentially acts in the lymph nodes. Programmed death 1 (PD-1) is expressed on T-cells, B-cells, monocytes, and dendritic cells (2). PD-L1 is a ligand of PD-1 and expressed on cancer cells, T-cells, B-cells, dendritic cells, and pancreatic cells (2). The PD-1/PD-L1 pathway is mainly involved in the tumor microenvironment. These molecules are referred to as immune checkpoints.

Immune checkpoint inhibitors (ICIs) are antibodies to these molecules and are promising novel agents for malig- nant tumor treatment $(3,4)$. ICIs promote T-cell-mediated cytotoxicity directed at cancer cell antigens. They have been reported to improve the prognosis of patients with malignant melanoma, renal cell cancer, non-small cell lung cancer, and Hodgkin's lymphoma $(3,4)$. Approximately $20-30 \%$ of patients with advanced cancer were found to be responders of ICIs.

However, various adverse effects have been reported as immune-related adverse effects (irAEs). IrAEs include dermatological, gastrointestinal, hepatic, neurological, and endocrine disorders (3-12). In the endocrine system, irAEs in the pituitary glands $(3,5)$, thyroid glands $(6,7)$, parathyroid glands (8), pancreas (3-5, 9-11), and adrenal glands (12) have been reported. Regarding pancreatic irAEs, patients with type 1 diabetes or fulminant type 1 diabetes mellitus (F1DM) after the administration of anti-PD-1 antibodies

${ }^{1}$ The First Department of Medicine, Wakayama Medical University, Japan and ${ }^{2}$ Department of Dermatology, Wakayama Medical University, Japan

Received: May 16, 2017; Accepted: November 15, 2017; Advance Publication by J-STAGE: February 28, 2018

Correspondence to Dr. Hidefumi Inaba, inaba@wakayama-med.ac.jp 


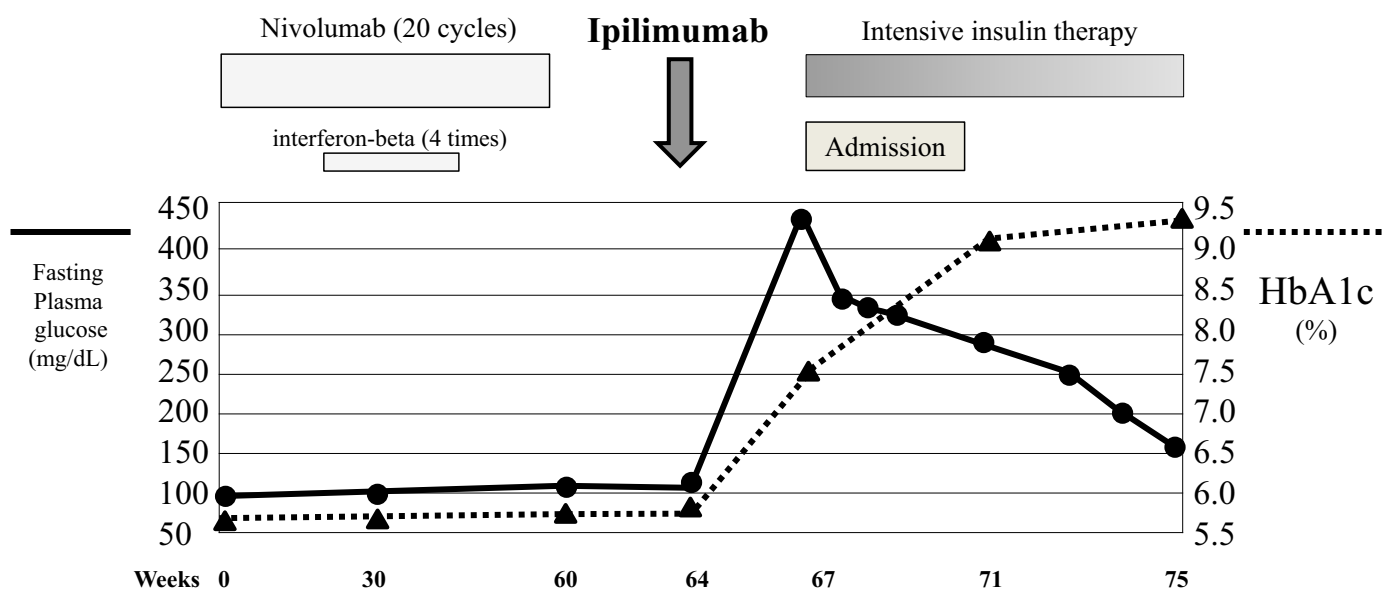

Figure 1. The clinical course after the initiation of nivolumab. After switching to ipilimumab, acute hyperglycemia and the development of F1DM were seen. The commencement of intensive insulin therapy improved the plasma glucose levels.

have been described $(3-5,9)$ as a rare presentation of irAEs. In addition, F1DM with anti-PD-1 antibody after treatment with anti-CTLA-4 antibody (10) and F1DM with both antibodies simultaneously (11) have also been reported. However, F1DM associated with anti-CTLA-4 antibody is rarely seen.

We herein report a case of F1DM induced by anti-CTLA4 antibody after the discontinuation of anti-PD-1 antibody, raising possible mechanisms of F1DM with ICIs, and highlighting appropriate clinical follow-up and diagnostic approaches of F1DM during ICI therapy.

\section{Case Report}

An 80-year-old woman had been diagnosed with malignant melanoma in the right foot 3 years earlier and underwent surgery several times. Anti-PD-1 antibody (nivolumab, $2 \mathrm{mg} / \mathrm{kg}$ every 3 weeks) therapy had been started 16 months earlier, and 20 cycles of the treatment had been carried out (Fig. 1). She underwent interferon-beta therapy four times at four-week intervals one year before transiently with nivolumab. She showed a normal glucose tolerance during nivolumab and interferon-beta therapy (HbA1c $\leq 6.0 \%)$. Due to the progression of her disease (TisM3N0, stage IIIc, progression of pulmonary metastasis suspected), nivolumab was discontinued and changed to anti-CTLA-4 antibody (ipilimu$\mathrm{mab}, 3 \mathrm{mg} / \mathrm{kg}$ ).

Twenty days later, she developed sudden thirst and visited our hospital. On admission, she exhibited polydipsia and polyuria. She had no smoking or drinking history, and her medical history was unremarkable. Her body height was 153 $\mathrm{cm}$, and her weight was $51 \mathrm{~kg}$ (BMI, $\left.21.8 \mathrm{~kg} / \mathrm{m}^{2}\right)$. Her blood pressure was $152 / 83 \mathrm{mmHg}$, her heart rate was 92 beats/min and regular, and her body temperature was $36.9^{\circ} \mathrm{C}$. Her thyroid gland was firm and not enlarged. No abnormal heart or lung sounds were detected. No lymph node swelling was observed. In the laboratory test (Table 1A), her plasma glucose was elevated to $639 \mathrm{mg} / \mathrm{dL}$,
HbA1c was $7.7 \%$, and her fasting serum C-peptide immunoreactivity (CPR) was $<0.01 \mathrm{ng} / \mathrm{mL}$ (normal range, 0.9 $3.8 \mathrm{ng} / \mathrm{mL}$ ). Anti-glutamic acid decarboxylase (GAD) and anti-insulinoma-associated protein-2 (IA-2) antibodies were negative. Urinary ketone body was $1+$. Serum ketone bodies were marginally increased (data not shown). Thrombocytopenia had been observed before the start of nivolumab treatment (day $0 ; 12.2 \times 10^{4} / \mu \mathrm{L}$ ) and it later worsened after ipilimumab treatment (day $12 ; 12.0 \times 10^{4} / \mu \mathrm{L}$, and day $20 ; 8.6$ $\times 10^{4} / \mu \mathrm{L}$, shown in Table $1 \mathrm{~A}$ ). Hyponatremia due to hyperglycemia was seen. Her hepatic and renal functions were normal. Remarkably, anti-insulin antibody was converted to positive $(1.8 \%$, normal range, $<0.4)$ after administration of ipilimumab (Fig. 1 and Table 1A). Although antinuclear antibodies were increased (Table 1B), individual antibodies suggesting collagen diseases were all negative (data not shown). Hypocomplementemia was not seen. The serum soluble interleukin-2 receptor (sIL2R) level was elevated, as was the serum Sialylated Carbohydrate Antigen, Krebs von den Lungen-6 (KL-6) level. The levels of SP-A and SP-D were normal. In endocrinological and immunological examinations (Table 1B), the pituitary, parathyroid, thyroid, and adrenal functions were all normal. Thyroid autoantibodies (TgAb, TPOAb, and TRAb-3rd generation) were negative. She was found to have Human Leukocyte Antigen (HLA)DR4 allele (Table 1B).

No abnormal shadows other than pulmonary metastasis were seen on chest X-ray (figure not shown). Electrocardiogram showed a normal sinus rhythm and no ST-T changes (figure not shown). On an ultrasonographic examination, her thyroid gland was normal in size (figure not shown). On abdominal computed tomography (CT), the pancreas was not remarkably enlarged on admission (Fig. 2). The accumulation of fluorodeoxyglucose (FDG) on positron emission tomography (PET) was observed in the pulmonary metastasis and not observed in the pancreas before ipilimumab treatment (figure not shown). Based on the results above, she was diagnosed with F1DM (13), and intravenous insulin in- 
Table 1A. Laboratory Data on Admission.

\begin{tabular}{|c|c|c|c|c|}
\hline WBC &, $990 / \mu \mathrm{L}$ & PG & $\underline{639} \mathrm{mg} / \mathrm{dL}$ & \\
\hline (Neutro 73.4 & $.4 \%$, Eos $0.5 \%$, Lym $15 \%)$ & $\mathrm{HbA1c}$ & $7.7 \%$ & \\
\hline $\mathrm{Hb}$ & $12.8 \mathrm{~g} / \mathrm{dL}$ & Glucagon & $173 \mathrm{pg} / \mathrm{mL}$ & $(71-174)$ \\
\hline Plt & $\underline{8.6} \times 10^{4} / \mu \mathrm{L}$ & Fasting C-peptide & $\leq 0.01 \mathrm{ng} / \mathrm{mL}$ & $(0.9-3.8)$ \\
\hline AST & $21 \mathrm{IU} / \mathrm{L}$ & Anti-GAD antibody & $<5.0 \mathrm{U} / \mathrm{mL}$ & $(<5.0)$ \\
\hline ALT & $20 \mathrm{IU} / \mathrm{L}$ & Anti-IA2 antibody & $<0.4 \mathrm{U} / \mathrm{mL}$ & $(<0.4)$ \\
\hline$\gamma$-GTP & $26 \mathrm{IU} / \mathrm{L}$ & Anti-insulin $\mathrm{Ab}$ & $\underline{1.8} \%$ & $(<0.4)$ \\
\hline ALP & $377 \mathrm{IU} / \mathrm{L}$ & & & \\
\hline BUN & $24 \mathrm{mg} / \mathrm{dL}$ & ANA & $\times \underline{320}$, speckled & $(<40)$ \\
\hline $\mathrm{Cr}$ & $0.77 \mathrm{mg} / \mathrm{dL}$ & $\mathrm{C} 3$ & $95 \mathrm{mg} / \mathrm{dL}$ & $(65-135)$ \\
\hline T-bil & $1.4 \mathrm{mg} / \mathrm{dL}$ & $\mathrm{C} 4$ & $23 \mathrm{mg} / \mathrm{dL}$ & $(13-35)$ \\
\hline $\mathrm{Na}$ & $\underline{129} \mathrm{mEq} / \mathrm{L}$ & $\mathrm{CH} 50$ & $50.0 \mathrm{U} / \mathrm{mL}$ & $(30-50)$ \\
\hline K & $\underline{5.0} \mathrm{mEq} / \mathrm{L}$ & KL-6 & $\underline{514} \mathrm{U} / \mathrm{mL}$ & $(<500)$ \\
\hline $\mathrm{Cl}$ & $\underline{95} \mathrm{mEq} / \mathrm{L}$ & SP-A & $26.4 \mathrm{ng} / \mathrm{mL}$ & $(<43.8)$ \\
\hline AMY & $47 \mathrm{IU} / \mathrm{L} \quad(40-122)$ & SP-D & $73.5 \mathrm{ng} / \mathrm{mL}$ & $(<110)$ \\
\hline CRP & $0.07 \mathrm{mg} / \mathrm{dL}(<0.30)$ & sIL2R & $\underline{1,125} \mathrm{U} / \mathrm{mL}$ & $(145-519)$ \\
\hline \multicolumn{2}{|c|}{ Urinary analysis } & \multicolumn{3}{|c|}{ Arterial blood gas analysis } \\
\hline Protein & $(-)$ & $\mathrm{pH}$ & 7.432 & \\
\hline Occult bloo & $(-)$ & $\mathrm{pCO}_{2}$ & $35.4 \mathrm{mmHg}$ & \\
\hline Sugar & $\underline{(4+)}$ & $\mathrm{pO}_{2}$ & $84.7 \mathrm{mmHg}$ & \\
\hline Ketone & $(1+)$ & $\mathrm{HCO}_{3}$ & $23.2 \mathrm{mmol} / \mathrm{L}$ & \\
\hline
\end{tabular}

Footnote: underline denote abnormal values.

ANA: anti-nuclear antibody, sIL2R: serum soluble interleukin-2

Table 1B. Endocrinological and Immunological Tests on Admission.

\begin{tabular}{|c|c|c|c|c|c|}
\hline TSH & $2.22 \mu \mathrm{IU} / \mathrm{mL}$ & $(0.35-4.94)$ & FACS analysis: & & \\
\hline FT3 & $2.25 \mathrm{pg} / \mathrm{mL}$ & $(1.71-3.71)$ & $\mathrm{CD}^{+}{ }^{\mathrm{T}}$-cell & $\underline{69.1} \%$ & $(75-85)$ \\
\hline FT4 & $1.52 \mathrm{ng} / \mathrm{dL}$ & $(0.70-1.55)$ & CD19+B-cell & $11.8 \%$ & $(5-15)$ \\
\hline TRAb-3 & $<0.9 \mathrm{IU} / \mathrm{mL}$ & $(<2.0)$ & $\mathrm{CD} 4^{+} \mathrm{T}-\mathrm{cell}$ & $\underline{55.7} \%$ & $(35-55)$ \\
\hline $\operatorname{TgAb}$ & $<10.0 \mathrm{IU} / \mathrm{mL}$ & $(<28.0)$ & $\mathrm{CD}^{+}{ }^{+} \mathrm{T}-$ cell & $\underline{11.2} \%$ & $(19-37)$ \\
\hline TPOAb & $<5.0 \mathrm{U} / \mathrm{mL}$ & $(<16.0)$ & $\mathrm{CD} 4 / \mathrm{CD} 8$ & $\underline{4.97}$ & $(1-1.5)$ \\
\hline Cortisol & $16.9 \mu \mathrm{g} / \mathrm{dL}$ & $(2.9-19.4)$ & & & \\
\hline $\mathrm{ACTH}$ & $18.5 \mathrm{pg} / \mathrm{mL}$ & $(7.2-63.3)$ & Th1 & $25.1 \%$ & \\
\hline PRA & $\underline{3.9} \mathrm{ng} / \mathrm{mL} / \mathrm{h}$ & $(0.2-2.7)$ & Th2 & $2.9 \%$ & \\
\hline PAC & $15.6 \mathrm{pg} / \mathrm{mL}$ & $(3.6-24)$ & Th1/Th2 & 8.7 & \\
\hline GH & $0.1 \mathrm{ng} / \mathrm{mL}$ & $(0-2.1)$ & $\mathrm{CD} 4^{+} \mathrm{CD} 25^{+}$ & $11.9 \%$ & $(6.0-21.0)$ \\
\hline IGF-I & $51 \mathrm{ng} / \mathrm{mL}$ & $(49-158)$ & CD4- CD25+ & $3.3 \%$ & $(2.0-14.0)$ \\
\hline LH & $\underline{33.1} \mathrm{mIU} /$ & $(1.7-11.2)$ & $\mathrm{CD} 4{ }^{+} \mathrm{CD} 25-$ & $48.6 \%$ & $(15.0-39.0)$ \\
\hline FSH & $\underline{\mathrm{mL}}$ & $(2.1-18.6)$ & CD4- CD25- & $36.2 \%$ & $(37.0-69.0)$ \\
\hline E2 & $<5 \mathrm{pg} / \mathrm{mL}$ & $(<10)$ & & & \\
\hline P4 & $0.2 \mathrm{ng} / \mathrm{mL}$ & $(0.1-0.8)$ & & & \\
\hline PRL & $14.3 \mathrm{ng} / \mathrm{mL}$ & $(<15)$ & & & \\
\hline $\mathrm{ADH}$ & $1.1 \mathrm{pg} / \mathrm{mL}$ & $(0.3-4.2)$ & & & \\
\hline \multicolumn{6}{|c|}{ HLA-typing analysis: } \\
\hline \multicolumn{6}{|c|}{ HLA-A11, A26 } \\
\hline \multicolumn{6}{|c|}{ HLA-B61 } \\
\hline HLA-DR & , DR12 & & & & \\
\hline
\end{tabular}

Footnotes: underline denote abnormal values.

TSH: thyrotropin, FT3: triiodothyronine, FT4: thyroxine, TRAb-3: TSH receptor antibody (third generation), $\mathrm{TgAb}$ : anti-thyroglobulin antibody, TPOAb: anti-thyroid peroxidase antibody, ACTH: adrenocorticotropic hormone, PRA: plasma renin activity, PAC: plasma aldosterone concentration, GH: growth hormone, IGF-I: insulin-like growth factor-I, LH: luteinizing hormone, FSH: follicle stimulating hormone, E2: estradiol, P4: progesterone, PRL: prolactin, ADH: antidiuretic hormone 
fusion $(0.1$ unit $/ \mathrm{kg})$ followed by intensive subcutaneous insulin therapy was commenced. The dosage of insulin was increased (insulin lispro 10 units before breakfast, 8 units before lunch, and 8 units before dinner; insulin glargine 10 units before sleep) (Fig. 1). No diabetic complications, such as retinopathy, nephropathy, or neuropathy, were observed. The plasma glucose level was gradually decreased and settled at $100-180 \mathrm{mg} / \mathrm{dL}$ before each meal, and she was discharged. The level of anti-insulin antibody was gradually decreased and the level of KL-6 improved over the next eight weeks (Table 2). The platelet counts also recovered to the level observed before the start of ipilimumab treatment (data not shown). Anti-GAD antibody levels were normal throughout the course. In a fluorescence activated cell sorting analysis, a decreased proportion of $\mathrm{CD}^{+} \mathrm{T}$-cells, an increased proportion of $\mathrm{CD}^{+} \mathrm{T}$-cells, and a decreased proportion of $\mathrm{CD}^{+} \mathrm{T}$-cells concomitant with an increased CD4/ CD8 ratio were consistent with the treatment of nivolumab and ipilimumab. The ratio of Th1/Th2 and the $\mathrm{CD} 4^{+} \mathrm{CD} 25^{+}$ proportion were within normal ranges. The re-administration of ipilimumab is now being considered after a systematic examination of the disease activity of malignant melanoma.

\section{Discussion}

The current report showed a case of F1DM, accompanied by positive conversion of anti-insulin antibody, by administration of ipilimumab after the discontinuation of nivolumab. A diagnosis of F1DM was made based on an

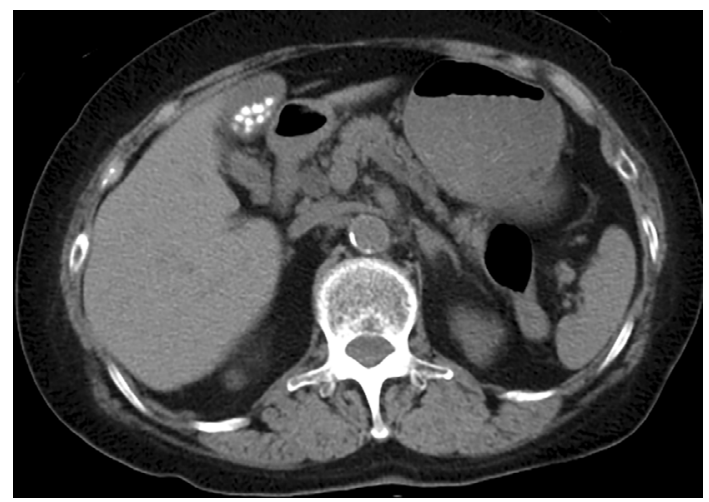

Figure 2. On admission, the pancreas was not remarkably enlarged on abdominal CT.
HbA1c $<8.5 \%$, plasma glucose $>288 \mathrm{mg} / \mathrm{dL}$, positivity of ketone bodies, and fasting CPR $<0.3 \mathrm{ng} / \mathrm{mL}$, according to the criteria (13).

Before starting ipilimumab therapy, the levels of antiinsulin antibody had been negative $(<0.4 \%)$ during nivolumab and interferon-beta therapy. Therefore, ipilimumab was deemed the most responsible for inducing antiinsulin immunity in this case. Interferon-beta might affect the development of diabetes with seroconversions of autoantibodies (14), and nivolumab might also be involved with F1DM (3-5, 9-11), as reported previously. Although ICIs activate T-cells through the inhibition of immune-checkpoint molecules, the etiology of irAEs induced by ICIs has been unclear, and the clinical significance of the positivity of anti-GAD, anti-IA2, and anti-insulin antibodies is still unknown. In the current case, the development of F1DM and positive conversion of anti-insulin antibody suggest the activation of anti-pancreatic beta cell-specific immunity. Bowyer et al. reported that grade 3-4 irAEs (colitis, diarrhea, pneumonitis, hepatitis, and encephalitis) developed in $35 \%$ of patients with melanoma who received anti-CTLA-4 antibody after the discontinuation of anti-PD-1 antibody (15). Imafuku et al. also reported that all cases who received antiCTLA-4 antibody after discontinuation of anti-PD-1 antibody, developed grade 3-4 irAEs (rash, colitis, and hepatitis) (16). However, no endocrine-related irAEs were described in those reports. Although a higher frequency of irAEs is observed when using ipilimumab after nivolumab or with dual administration, reverse sequence (nivolumab after ipilimumab) treatment did not increase the frequency of irAEs (7). One possible mechanism underlying the higher frequency of irAE with the nivolumab-ipilimumab sequence is as follows: anti-PD-1 antibodies bind to their receptors with high occupancy, making PD-1-positive immune cell populations predominant over the subsequent several months (17).

The occurrence of F1DM with ICIs concurrent with F1DM-associated allele HLA-DR4 (13) raises the possibility of cross-reactivity being involved with insulin antigen and malignant melanoma antigen, as is seen with cases of thyroid autoimmune disorders with NY-ESO-1 vaccination (18).

Zarour et al. reported that the HLA-DR4-restricted melanoma antigen Melan-A/MART-1(51-73) was recognized by melanoma-reactive CD4 ${ }^{+}$T-cells (19). Mannering et al. iden-

Table 2. Laboratory Data during the Course.

\begin{tabular}{llcccc}
\hline & & $\begin{array}{c}\text { Four weeks } \\
\text { before admission }\end{array}$ & On admission & $\begin{array}{c}\text { Four weeks after } \\
\text { admission }\end{array}$ & $\begin{array}{c}\text { Eight weeks } \\
\text { after admission }\end{array}$ \\
\hline Anti-insulin $\mathrm{Ab}$ & $\%(<0.4)$ & 0.4 & $\underline{1.8}$ & $\underline{1.1}$ & $\underline{\mathbf{5 1 4}}$ \\
$\mathrm{KL}-6$ & $\mathrm{U} / \mathrm{mL}(<500)$ & 416 & $\underline{\mathbf{7 . 7}}$ & $\underline{9.1}$ & $\underline{\mathbf{5 0 8}}$ \\
$\mathrm{HbA} 1 \mathrm{c}$ & $\%$ & 6.0 & $<5.0$ & $<5.0$ & $<5.0$ \\
$\mathrm{Anti-GAD} \mathrm{Ab}$ & $\mathrm{U} / \mathrm{mL}(<0.5)$ & $\mathrm{ND}$ & $<0.4$ & $\mathrm{ND}$ & $\mathrm{ND}$ \\
$\mathrm{Anti-IA2} \mathrm{Ab}$ & $\mathrm{U} / \mathrm{mL}(<0.4)$ & $\mathrm{ND}$ & & \\
\hline
\end{tabular}

Footnotes: underline denote abnormal values.

ND: not determined 
tified the HLA-DR4 restricted insulin A-chain epitope (A113 ) in type $1 \mathrm{DM}$ (T1DM) patients (20). In addition, HLADR4 is a known risk factor of T1DM as well as F1DM (21). Thus, patients who have HLA-DR4 molecules with F1DM and malignant melanoma may possess autoreactivity to both insulin and melanoma antigens. The activation of anti-insulin and anti-melanoma immunity may induce the exacerbation of F1DM and improvement of malignant melanoma. Insulin antigen exposure is known to be involved with cross-presentation on the surface of MHC molecules, and subsequently, epitope spreading of autoantigens and alloantigens may occur. As with HLA-class II molecules (although HLA-DQ was not determined in this case), HLAclass I molecules may also play an important role in the development of F1DM. In addition to HLA mutations, CTLA4, INS, PD-L1, and PD-1 gene mutations may contribute to the development of T1DM (21-23), although those were not examined in the present case. In addition, a low expression of the PD-1 gene in association with T1DM (24) and a low expression of the CTLA-4 gene in association with F1DM (25) have been reported.

Anti-CTLA-4 antibody often induces autoimmunity via the suppression of the regulatory T-cell (Treg) function (1). In our case, although the proportion of $\mathrm{CD}^{+} \mathrm{CD} 25^{+} \mathrm{T}$-cells [roughly similar in proportion to Tregs, but not precisely reflecting the Treg attribution, with a specific hallmark of FoxP3 (26)] was normal, the Treg function might have been attenuated after ipilimumab treatment. Interestingly, the increased expression of CTLA-4 in the pituitary gland was reported to be related to severe hypophysitis, based on type II or IV allergy induced by IgG1- (ipilimumab) or IgG2-type anti-CTLA-4 antibodies (27). However, such an allergic mechanism in the pancreas was not observed in this case. Anti-PD-1 and anti-PD-L1 antibodies activate $\mathrm{CD}^{+}$and CD4 $4^{+}$-cells, thereby strengthening cytotoxic and helper/inducer activity, respectively (2).

In animal studies, CTLA-4 pathway was reported to be associated with the development of T1DM in neonate NOD mice (28), and PD-1 blockade was reported to induce T1DM in mice (29),

In the absence of intestinal pneumonia with normal levels of SP-A and SP-D, the elevated levels of KL-6 seemed to be characteristic of our case. KL-6 is often used as a marker of intestinal pneumonia and is also expressed in the pancreatic duct. Thus, the KL-6 positivity noted in the current case may indicate damage of the pancreas (30). Although the serum amylase level was normal and no obvious symptoms of pancreatitis were seen, pancreatic damage might exist. The sIL2R level was increased in the current case. sIL2R is secreted from T-cells. Assuming that T-cells are activated by the use of ICIs, especially ipilimumab, elevated levels of sIL2R may be a marker of the initiation of F1DM.

Despite severe hyperglycemia, acidosis was not seen in our present case, and urinary and serum ketone bodies were slightly elevated. Thus, F1DM due to ICIs might have different entities from F1DM with other etiologies. The rela- tionship between the mild manifestation of F1DM and the seroconversion of autoantibodies should be investigated in the future. Transient increases in anti-insulin antibody may raise the possibility of a non-specific reaction, but the positivity of the antibody was the most important finding and a reliable biomarker in our case. Therefore, anti-insulin antibody positivity may be used as a disease hallmark of F1DM due to ICIs.

Future studies should try to identify individuals who are susceptible to irAEs. HLA type, age, gender, tumor type, intervention timing, and the correlation with anti-tumor immunity appear to be useful for such an identification $(3,4)$.

In conclusion, pancreatic beta cell-specific immunity was considered to have been activated after the administration of ipilimumab in the present case. The effects of interferonbeta and nivolumab on the development of F1DM were also possible. Assessing the levels of KL-6 and sIL2R may help achieve an earlier diagnosis of F1DM. Further investigations with more cases over longer periods of time are warranted to establish effective diagnostic and therapeutic approaches for F1DM with ICI.

The authors state that they have no Conflict of Interest (COI).

\section{References}

1. Blank CU, Enk A. Therapeutic use of anti-CTLA-4 antibodies. Int Immunol 27: 3-10, 2015.

2. Okazaki T, Honjo T. PD-1 and PD-1 ligands: from discovery to clinical application. Int Immunol 19: 813-824, 2007.

3. Hodi FS, O'Day SJ, McDermott DF, et al. Improved survival with ipilimumab in patients with metastatic melanoma. N Engl J Med 19;363: 711-723, 2010.

4. Topalian SL, Hodi FS, Brahmer JR, et al. Safety, activity, and immune correlates of anti-PD-1 antibody in cancer. $\mathrm{N}$ Engl $\mathrm{J}$ Med 28;366: 2443-2454, 2012.

5. Torino F, Corsello SM, Salvatori R. Endocrinological side-effects of immune checkpoint inhibitors. Curr Opin Oncol 28: 278-287, 2016.

6. Corsello SM, Barnabei A, Marchetti P, De Vecchis L, Salvatori R, Torino F. Endocrine side effects induced by immune checkpoint inhibitors. J Clin Endocrinol Metab 98: 1361-1375, 2013.

7. Weber JS, D'Angelo SP, Minor D, et al. Nivolumab versus chemotherapy in patients with advanced melanoma who progressed after anti-CTLA-4 treatment (CheckMate 037): a randomised, controlled, open-label, phase 3 trial. Lancet Oncol 16: 375-384, 2015.

8. Win MA, Thein KZ, Qdaisat A, Yeung SJ. Acute symptomatic hypocalcemia from immune checkpoint therapy-induced hypoparathyroidism. Am J Emerg Med 35: 1039.e5-1039.e7, 2017.

9. Chae YK, Chiec L, Mohindra N, Gentzler R, Patel J, Giles F. A case of pembrolizumab-induced type-1 diabetes mellitus and discussion of immune checkpoint inhibitor-induced type 1 diabetes. Cancer Immunol Immunother 66: 25-32, 2017.

10. Gaudy C, Clévy C, Monestier S, et al. Anti-PD1 Pembrolizumab can induce exceptional fulminant type 1 diabetes. Diabetes Care 38: e182-e183, 2015.

11. Teló GH, Carvalhal GF, Cauduro CGS, Webber VS, Barrios $\mathrm{CH}$, Fay AP. Fulminant type 1 diabetes caused by dual immune checkpoint blockade in metastatic renal cell carcinoma. Ann Oncol 28: 191-192, 2017.

12. Trainer H, Hulse P, Higham CE, Trainer P, Lorigan P. Hyponatrae- 
mia secondary to nivolumab-induced primary adrenal failure. Endocrinol Diabetes Metab Case Rep [Internet]. 2016 Nov 1.

13. Shibasaki S, Imagawa A, Hanafusa T. Fulminant type 1 diabetes mellitus: a new class of type 1 diabetes. Adv Exp Med Biol 771: 20-23, 2012.

14. Nakamura K, Kawasaki E, Imagawa A, et al. Type 1 diabetes and interferon therapy: a nationwide survey in Japan. Diabetes Care 34: 2084-2089, 2011.

15. Bowyer S, Prithviraj P, Lorigan P, et al. Efficacy and toxicity of treatment with the anti-CTLA-4 antibody ipilimumab in patients with metastatic melanoma after prior anti-PD-1 therapy. Br J Cancer 114: 1084-1089, 2016.

16. Imafuku K, Yoshino K, Yamaguchi K, Tsuboi S, Ohara K, Hata $\mathrm{H}$. Comment on 'Efficacy and toxicity of treatment with the antiCTLA-4 antibody ipilimumab in patients with metastatic melanoma after prior anti-PD-1 therapy'. Br J Cancer 116: e14, 2017.

17. Brahmer JR, Drake CG, Wollner I, et al. Phase I study of singleagent anti-programmed death-1 (MDX-1106) in refractory solid tumors: safety, clinical activity, pharmacodynamics, and immunologic correlates. J Clin Oncol 28: 3167-3175, 2010.

18. Vita R, Guarneri F, Agah R, Benvenga S. Autoimmune thyroid disease elicited by NY-ESO-1 vaccination. Thyroid 24: 390-394, 2014.

19. Zarour HM, Kirkwood JM, Kierstead LS, et al. Melan-A/MART-1 (51-73) represents an immunogenic HLA-DR4-restricted epitope recognized by melanoma-reactive CD4(+) T cells. Proc Natl Acad Sci U S A 97: 400-405, 2000.

20. Mannering SI, Harrison LC, Williamson NA, et al. The insulin Achain epitope recognized by human $\mathrm{T}$ cells is posttranslationally modified. J Exp Med 202: 1191-1197, 2005.

21. Pociot F, Lernmark Å. Genetic risk factors for type 1 diabetes. Lancet 387: 2331-2339, 2016.

22. Noble JA, Valdes AM. Genetics of the HLA region in the predic- tion of type 1 diabetes. Curr Diab Rep 11: 533-542, 2011.

23. Pizarro C, García-Díaz DF, Codner E, Salas-Pérez F, Carrasco E, Pérez-Bravo F. PD-L1 gene polymorphisms and low serum level of PD-L1 protein are associated to type 1 diabetes in Chile. Diabetes Metab Res Rev 30: 761-766, 2014.

24. Fujisawa R, Haseda F, Tsutsumi C, et al. Low programmed cell death-1 (PD-1) expression in peripheral CD4(+) T cells in Japanese patients with autoimmune type 1 diabetes. Clin Exp Immunol 180: 452-457, 2015.

25. Imagawa A, Hanafusa T. Fulminant type 1 diabetes--an important subtype in East Asia. Diabetes Metab Res Rev 27: 959-964, 2011.

26. Hori S, Nomura T, Sakaguchi S. Control of regulatory T cell development by the transcription factor Foxp3. Science 299: 10571061, 2003.

27. Caturegli P, Di Dalmazi G, Lombardi M, et al. Hypophysitis secondary to cytotoxic T-lymphocyte-associated protein 4 blockade: insights into pathogenesis from an autopsy series. Am J Pathol 186: 3225-3235, 2016.

28. Ansari MJ, Salama AD, Chitnis T, et al. The programmed death-1 (PD-1) pathway regulates autoimmune diabetes in nonobese diabetic (NOD) mice. J Exp Med 198: 63-69, 2003.

29. Kochupurakkal NM, Kruger AJ, Tripathi S, et al. Blockade of the programmed death-1 (PD1) pathway undermines potent genetic protection from type 1 diabetes. PLoS One 9: e89561, 2014.

30. Ohtsuki Y, Watanabe R, Kimura M, et al. Usefulness of KL-6 in the subtyping of intraductal papillary mucinous neoplasia of the pancreas, including carcinoma, dysplasia, and hyperplasia. Med Mol Morphol 48: 85-91, 2015.

The Internal Medicine is an Open Access article distributed under the Creative Commons Attribution-NonCommercial-NoDerivatives 4.0 International License. To view the details of this license, please visit (https://creativecommons.org/licenses/ by-nc-nd/4.0/).

(C) 2018 The Japanese Society of Internal Medicine Intern Med 57: 2029-2034, 2018 